7. Reprod. Fert. (1971) 24, 409-413

\title{
ALTERATIONS IN SIALIC ACID IN THE EPIDIDYMIS OF THE PUBERAL RAT IN RESPONSE TO CHANGES IN FUNCTIONAL ACTIVITY OF THE TESTIS
}

\author{
M. RAJALAKSHMI AND M. R. N. PRASAD \\ Department of Zoology, Delhi University, Delhi-7, India \\ (Received 15th May 1970, revised 10th August 1970)
}

\begin{abstract}
Summary. Ghanges in the secretory activity of the epididymis and accessory glands were studied in the rat during the transition from the prepuberal to the puberal state. Administration of ORF 1616 or cyproterone acetate, either alone or in combination, decreased the levels of sialic acid and protein in the caput and cauda epididymidis. The significance of these changes is discussed in relation to the physiology of the epididymis of the puberal rat.
\end{abstract}

\section{INTRODUCTION}

Ghanges such as fluctuation in the normal levels of circulating androgens or the flow of testicular fluid and spermatozoa, which involve the internal milieu of the epididymis of an adult rat, are also known to alter its physiology (Gustafsson, 1966). The sialic acid content of the epididymis of an albino rat is affected by the initial passage of spermatozoa from the testes during its transition from the prepuberal to the puberal state (Rajalakshmi \& Prasad, 1969). It was, therefore, of interest to evaluate the factors (androgens or spermatozoa) that affect the physiology of the epididymis by altering the androgenic and/or the gametogenic functions of the testes, using epididymal sialic acid as a parameter.

\section{MATERIALS AND METHODS}

Albino rats of the Holtzman strain were kept in an air-conditioned room $\left(78 \pm 2^{\circ} \mathrm{F}\right)$ and fed a standard diet with unrestricted access to water. The animals were divided into four groups and were subjected to the following treatments:

Group I. Immature 30-day-old rats were given ORF 1616 (1-( $\mathcal{N}-\mathcal{N}$-diethyl carbomylmethyl)-2-4-dinitropyrrole) suspended in propylene glycol at a dose of $500 \mathrm{mg} / \mathrm{kg} / \mathrm{rat}$ on Days 30 and 40 by oral gavage.

Group II. Immature 40-day-old rats were treated with cyproterone acetate (6-chlor $\Delta^{6}-1,2 \alpha$-methylen-17 $\alpha$-hydroxyprogesterone acetate) in olive oil at a dose of $2 \mathrm{mg} / \mathrm{kg} / \mathrm{rat}$ from Days 40 to 50 .

Group III. Immature rats treated with $500 \mathrm{mg}$ of ORF $1616 / \mathrm{kg} / \mathrm{rat}$ on Days 30 and 40, were given $2 \mathrm{mg}$ of cyproterone acetate/day/rat from Days 40 to 50 . 

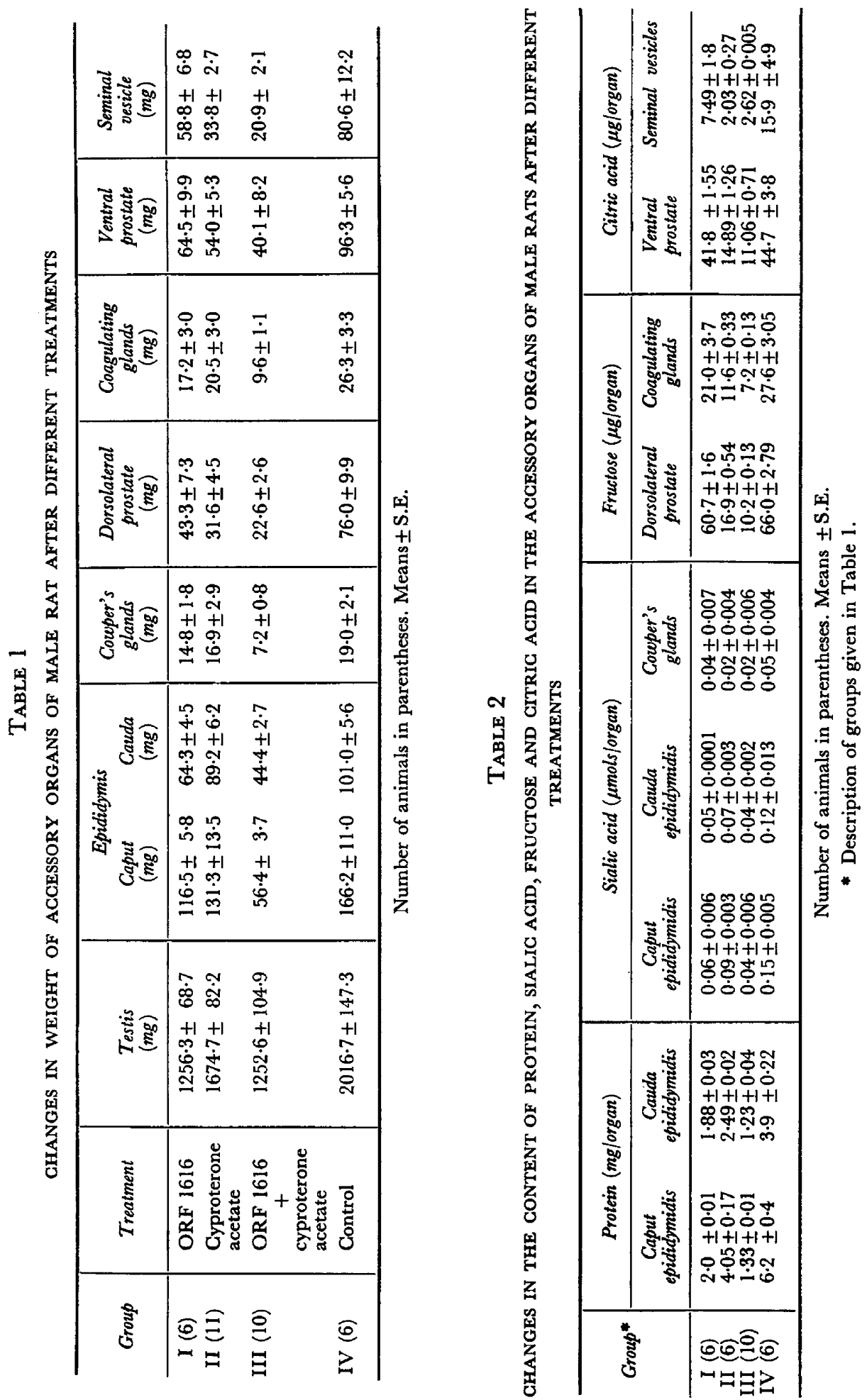
Group IV. Autopsies were performed on untreated animals which served as controls on Day 50. The rats in the treated groups were killed on Day 50.

At autopsy, the testis, epididymis and accessory glands were removed and weighed. Citric acid was estimated in the seminal vesicles and ventral prostate (Ettinger, Goldbaum \& Smith, 1952), fructose in the dorsolateral prostate and coagulating glands (Roe, 1934) and sialic acid in the Cowper's glands and in the caput and cauda epididymidis of one side (Warren, 1959). The caput and cauda epididymidis of the contralateral side were used for the estimation of protein (Gornall, Bardawill \& David, 1949). At the time of autopsy, smears of the corpus epididymidis were checked for the presence of spermatozoa. Groups I to III showed no spermatozoa in the epididymis, whereas the control animals showed slightly motile spermatozoa in the epididymis.

\section{RESULTS}

The changes in the weight of the organs in the different groups are given in Table 1.

Administration of ORF 1616 on Days 30 and 40 (Group I) produced a significant $(P<0.001)$ decrease in content and concentration of sialic acid and in the content of protein in the caput and cauda epididymidis (Table 2). However, the content and concentration of sialic acid of the Cowper's glands remained unchanged in the treated rats when compared to those of the controls (Table 2). The content and concentration of fructose and citric acid in the accessory glands showed no significant change $(P>0.05)$ after administration of ORF 1616 (Table 2).

Cyproterone acetate treatment for 10 days from Days 40 to 50 (Group II) caused a significant decrease $(P<0.01)$ in content of sialic acid and protein $(P<0.001)$ in the caput and cauda epididymidis (Table 2). The content and concentration of sialic acid in the Cowper's glands and those of citric acid and fructose in the accessory glands were markedly decreased after the administration of the anti-androgen (Table 2).

Simultaneous treatment of rats with ORF 1616 and cyproterone acetate (Group III) produced a decrease in sialic acid content of the caput and cauda epididymidis and of the Cowper's glands and the content of protein of the caput and cauda epididymidis (Table 2). The concentration of sialic acid in the caput and cauda epididymidis showed a significant change $(P<0.001)$ from control levels; however, the decrease in content of sialic acid in the caput epididymidis (Group III) was not marked $(P>0 \cdot 05)$ when compared to that of rats treated with ORF 1616 alone (Group I). Simultaneous administration of ORF 1616 and cyproterone acetate caused a marked decrease $(P<0.05)$ in the content and concentration of fructose and citric acid in the accessory glands (Table 2).

\section{DISGUSSION}

Spermatozoa acquire the capacity for motility and fertilizing ability during their transit through the epididymis. The response of the epididymis to changes in its internal environment during the transition from a prepuberal to a 
puberal condition is of interest since, during this period, the epididymis is apparently highly sensitive to changes in the androgenic and gametogenic functions of the testes. Prepuberal condition refers to the period before entry of the first wave of spermatozoa into the epididymis and puberal condition indicates the state after the migration of spermatozoa.

ORF 1616, a dinitropyrrole compound, inhibits spermatogenesis at the primary spermatocyte stage and produces drastic cytological changes in steps 1 to 14 (Patanelli \& Nelson, 1964). In the present study, no spermatozoa were seen in the epididymis of rats treated with ORF 1616 and there was a significant decrease in sialic acid levels of the epididymis. ORF 1616 produced no change in the androgen production of the testis. This was reflected in the normal levels for the fructose values of the dorsolateral prostate and coagulating glands, the citric acid of the ventral prostate and seminal vesicles and the sialic acid levels of the Cowper's glands. Since androgenic activity of the testis is normal, the decreased amounts of epididymal sialic acid could be due either to the absence of spermatozoa or to a direct action of the drug on the epididymal epithelium. The former appears to be the more likely explanation since it is known that the epididymal canal is dependent not only on the normal circulating levels of androgens for the retention of its physiological integrity but also on the normal flow of testicular fluid and spermatozoa (Gustafsson, 1966).

The extensive investigations of Neumann, von Berswordt-Wallrabe, Elger, Steinbeck \& Hahn (1968) have shown that the synthetic steroid, cyproterone acetate, is a potent anti-androgen. Neumann \& von Berswordt-Wallrabe (1966) have suggested that the action of cyproterone acetate is one of competitive inhibition of testosterone action on the target sites. At the dose levels employed in the present study, cyproterone acetate decreased not only the levels of fructose, citric acid and sialic acid in the accessory glands, but also levels of sialic acid and protein in the epididymis. Accessory gland fructose and citric acid levels are known to be sensitive parameters of androgen action (Mann, 1964); sialic acid in Cowper's glands is yet another sensitive index of androgenic function (Rajalakshmi \& Prasad, 1968). It appears from our results that the secretory activity of the epididymis is markedly affected by cyproterone acetate treatment and is sensitive to fluctuations in the levels of circulating androgens.

Simultaneous administration of ORF 1616 and cyproterone acetate produces a significant decrease in levels of protein and sialic acid of the caput and cauda epididymidis. It also causes a significant decrease in content and concentration of fructose, citric acid and sialic acid in accessory glands. This may be due to the anti-androgenic effect of cyproterone acetate alone since ORF 1616 by itself does not produce any decrease in androgenicity.

From the present data, it is clear that the epididymis, during its transition from the prepuberal to the puberal state, is adversely affected by any factor that alters its internal milieu, namely a decrease in circulating levels of androgens or the normal passage of spermatozoa and/or testicular fluid. It is suggested that such changes are possibly due to modifications in the secretory activity of the epididymis since the protein and sialic acid contents of the caput and cauda epididymidis show the same pattern of fluctuations. The physiological significance of these changes is under investigation. 
The authors thank Professor B. R. Seshachar for his interest in this work. Our thanks are due to $\mathrm{Mr} \mathrm{S}$. G. Varma for technical assistance in animal care. The work was supported by grants from the Ford Foundation, Ministry of Health and Family Planning, Government of India, and the Indian Council of Medical Research. The authors are grateful to Dr F. Neumann of Schering AG, Berlin, and to Dr John W. Stein, Jr, Ortho Research Foundation, U.S.A., for generous supplies of cyproterone acetate and ORF 1616, respectively.

\section{REFERENCES}

EtTinger, R. H., Goldbaum, L. R. \& SMith, L. H., JR (1952) A simplified photometric method for the determination of citric acid in biological fluids. F. biol. Chem. 199, 531.

Gornall, A. G., Bardawill, G. J. \& David, M. M. (1949) Determination of serum proteins by means of the biuret reaction. 7. biol. Chem. 177, 751 .

Gustafsson, B. (1966) Luminal contents of the bovine epididymis under conditions of reduced spermatogenesis, luminal blockage and certain sperm abnormalities. Acta vet. scand. Suppl. 17, 1.

ManN, T. (1964) The biochemistry of semen and of the male reproductive tract, 2nd edn. Methuen, London.

Neumann, F. \& von Berswordt-Waltrabe, R. (1966) Effects of the androgen antagonist cyproterone acetate on the testicular structure, spermatogenesis and accessory sexual glands of testosteronetreated adult hypophysectomized rats. F. Endocr. 35, 363.

Neumann, F., von Berswordt-Wallrabe, R., Elger, W., Steinbeck, H. \& Hahn, J. D. (1968) Effects of anti androgens. Excerpta med. Int. Cong. Ser. 184, 823.

Patanelli, D. J. \& Nelson, W. O. (1964) A quantitative study of inhibition and recovery of spermatogenesis. Recent Prog. Horm. Res. 20, 491.

Rajalakshmi, M. \& Prasad, M. R. N. (1968) Changes in the sialic acid content of the accessory glands of the male rat. 7 . Endocr. $41,471$.

Rajalakshmi, M. \& Prasad, M. R. N. (1969) Changes in sialic acid in the testis and epididymis of the rat during the onset of puberty. 7. Endocr. 44, 379.

ROE, J. H. (1934) A colorimetric method for the determination of fructose in blood and urine. F. biol. Chem. 107, 15.

WArren, L. (1959) The thiobarbituric acid assay of sialic acids. 7. biol. Chem. 234, 1971. 